\title{
Planejamentos docentes a partir do PNAIC/2013: revisitando os estudos sobre sequência didática
}

\author{
Andréa Ramos de Oliveira \\ Universidade Estadual Paulista "Júlio de Mesquita Filho (UNESP), \\ Presidente Prudente, São Paulo, Brasil \\ andrearamos_os@hotmail.com \\ http://orcid.org/0000-0001-7998-4660 \\ Ana Luzia Videira Parisotto \\ Universidade Estadual Paulista "Júlio de Mesquita Filho (UNESP), \\ Presidente Prudente, São Paulo, Brasil \\ analu.videira@uol.com.br \\ http://orcid.org/0000-0001-9786-745X
}

DOI: http://dx.doi.org/10.21165/el.v47i2.1928

\begin{abstract}
Resumo
Este trabalho integra estudo de caso e analisa planejamentos de docentes de $3^{\circ}$ ano do ensino fundamental de duas escolas de Birigui/SP participantes do Pacto Nacional pela Alfabetização na Idade Certa (PNAIC). Observadas orientações sobre sequências didáticas (SDs) constantes em cadernos de formação e à luz de estudos de Dolz e Schneuwly (2004) e de apontamentos de Bueno e Kleiman (2017) sobre o material distribuído pelo MEC, discutem-se propostas de trabalho dos docentes e o ensino de língua materna, avaliando a incorporação ao trabalho cotidiano de concepções abordadas durante o programa. Os resultados apontam que atividades elaboradas não chegam a se configurar SDs, produções que têm o professor como principal interlocutor e a forte influência do livro didático. Defende-se o desenvolvimento de posturas reflexivas dos docentes e a formação continuada voltada ao trabalho com gêneros textuais para diminuir o insucesso escolar das crianças no que concerne à leitura e à escrita.
\end{abstract}

Palavras-chave: sequência didática; PNAIC; planejamentos docentes.

\section{Teacher planning from PNAIC/2013: revisiting studies on didactic sequences}

\begin{abstract}
This case study analyzes teaching plans of grade 3 teachers from two elementary schools in Birigui, São Paulo State, Brazil, which participate in PNAIC (National Pact for Learning to Read and Write at Proper Age). Based on the guidelines for didactic sequences (DSs) found in teacher education textbooks and research carried out by Dolz and Schneuwly (2004) and a study conducted by Bueno and Kleiman (in press) about the material distributed by MEC (Ministry of Education and Culture), this article discusses proposals for classroom activities and the teaching of mother tongue, assessing the incorporation of theories addressed by PNAIC into everyday teaching activities. Results indicate that the activities investigated do not constitute DSs; they are overly teacher-centered and greatly shaped and influenced by classroom textbooks. Therefore, it is suggested that teachers' reflective attitude should be promoted as well as their continued education focusing on classroom work with textual genres in order to improve students' reading and writing skills.
\end{abstract}

Keywords: didactic sequence; PNAIC; teaching plans. 


\section{Introdução}

A $5^{\mathrm{a}}$ meta do Plano Nacional de Educação (PNE) reafirmou o compromisso político e social da alfabetização como direito e salientou a exigência por ações que viabilizassem o seu alcance. O Pacto Nacional pela Alfabetização na Idade Certa (PNAIC), acordo formal entre Governo Federal, estados e municípios e entidades para firmar o compromisso de alfabetizar crianças até, no máximo, 8 anos de idade, ao final do ciclo de alfabetização, mostrou-se uma dessas alternativas. Com alto investimento financeiro - perto de $\mathrm{R} \$ 1,5$ bilhão para 2013 - e foco na formação continuada aos profissionais da educação, o PNAIC, em sua primeira edição, abordou Língua Portuguesa e envolveu 38 Instituições de Ensino Superior (IEs), 53 coordenadores estaduais, 5.424 coordenadores municipais, 78 coordenadores no âmbito das IES, 170 supervisores (IES), 645 formadores (IES), 15.950 orientadores de estudos e 317.462 professores alfabetizadores das redes estaduais e municipais de ensino. Por sua abrangência, foi caracterizado como "o maior programa de formação de professores já desenvolvido pelo Ministério da Educação - MEC” (BRASIL, 2015, p. 21).

É no contexto do Pacto como programa de formação continuada que foi desenvolvida a pesquisa de mestrado "As contribuições do PNAIC para a prática docente: o que pensam e fazem docentes do $3^{\circ}$ ano e gestores escolares", um estudo de caso que investigou as contribuições oportunizadas pelo programa, na área de Língua Portuguesa, à prática de professores do $3^{\circ}$ ano do Ensino Fundamental em duas escolas selecionadas da rede municipal de ensino de Birigui/SP, segundo o entendimento desses professores alfabetizadores e de gestores escolares.

\section{A metodologia: o caminho perseguido}

O estudo desenvolvido pautou-se por uma abordagem qualitativa, justificada pela intencionalidade explicitada de compreender como o PNAIC contribuiu para a melhoria da prática docente dos professores pesquisados. A opção por se realizar um estudo de caso pareceu a mais indicada por permitir que o fenômeno estudado pudesse ser analisado considerando-se as particularidades dos sujeitos, das escolas e do município selecionados.

Utilizaram-se para geração de dados, na pesquisa de mestrado, os instrumentos: entrevista coletiva, questionários, análise documental ${ }^{1}$ e observação de aulas. O tratamento das informações pautou-se pela análise de conteúdo (BARDIN, 2011).

Para este artigo, apresentam-se análises realizadas a partir de planejamentos de aulas elaborados por docentes pesquisados, após o advento do PNAIC, observadas as orientações acerca de sequências didáticas constantes nos cadernos de formação e à luz dos estudos de Dolz e Schneuwly (2004), bem como de apontamentos de Bueno e Kleiman (2017) sobre o material distribuído pelo MEC. Os planejamentos importam, ainda, para a análise das propostas de leitura e produção escrita que circulam na escola.

\footnotetext{
${ }^{1}$ Consideraram-se "documentos”, na dissertação, os ofícios, relatórios, dados do sistema informatizado do município pesquisado, dentre outras fontes de coleta de dados relativos à Secretaria Municipal de Educação. Como documentos das escolas, tomou-se o Projeto Político Pedagógico e os planos de aula. Foram consultados, ainda, os relatórios com os dados das avaliações externas priorizadas na análise.
} 
Foram determinadas cinco semanas planejadas pelos docentes - de 22 de fevereiro a 26 de fevereiro de 2016; de 25 de abril a 29 de abril de 2016; de 06 de junho a 10 de junho de 2016; de 13 de junho a 17 de junho de 2016; de 08 de agosto a 12 de agosto de 2016. As duas primeiras semanas solicitadas referem-se ao primeiro bimestre, sendo uma do início do período letivo e outra do final do referido bimestre; a terceira e quarta semanas são sequenciais, a fim de perceber a continuidade que é dada dentro do bimestre, no caso o segundo, aos gêneros trabalhados; a quinta semana selecionada é a primeira de aula do terceiro bimestre.

Evidencia-se, aqui, por meio dos planejamentos semanais elaborados por docentes das duas escolas pesquisadas, como o ensino de língua materna é planejado e se há incorporação do trabalho com sequência didática (doravante SD), permitindo que se analise de que forma o ensino de língua materna vem sendo realizado após a formação do PNAIC. Defende-se, ainda, que, por meio do desenvolvimento de posturas reflexivas dos docentes e com uma formação continuada voltada ao trabalho com gêneros textuais, com foco na elaboração de SDs, a escola, considerada a realidade nacional, terá a possibilidade de "fazer a diferença", para diminuir a exclusão e o insucesso escolar de suas crianças no que concerne à leitura e à escrita.

\section{A importância do planejar: ação docente com intencionalidade}

Planejar integra a rotina do professor e é ação intrínseca ao seu fazer. Freire (2011) defende a tomada consciente de decisões como exigência do ensinar. A consciência não nasce, pois, do espontaneísmo; é pensada, refletida, planejada. Porque tão importante, o PNAIC, em 2013, apresentou caderno específico sobre o tema - Planejamento e organização da rotina na alfabetização -, assumindo o pressuposto de que, "[...] para planejar as situações didáticas de modo autônomo e consciente, é preciso ter clareza sobre o que se quer ensinar e o que os aprendizes pensam sobre o que se pretende ensinar" (BRASIL, 2012, p. 5).

As questões relativas ao fazer docente têm suscitado estudos de longa data. Neder (1993, p. 71) discute que "[...] a metodologia utilizada pelo professor é um dos determinantes do fracasso escolar, um dos maiores problemas hoje, sem dúvida, da educação brasileira". Sem desconsiderar outros fatores determinantes, a autora considera que a perspectiva metodológica adotada pelo docente "[...] tem peso e consequências sérias para o ensino da linguagem, principalmente nas primeiras séries do primeiro grau", acrescentando que "[...] o suporte teórico que tenha sobre linguagem é fundamental para o encaminhamento de seu ensino, mesmo que ele não tenha consciência disso" (NEDER, 1993, p. 71). Quando se assume uma concepção dialógica de linguagem e se acredita na SD como uma rica possibilidade de trabalho com a leitura e produção de textos, deve-se, também, perseguir a reflexão sobre o que se planeja, sobre o que se faz e sobre como isso chega à criança.

O PNAIC trouxe cadernos sobre o trabalho com diferentes gêneros textuais Unidade 05 , "O trabalho com os diferentes gêneros textuais em sala de aula: diversidade e progressão escolar andando juntas" - e sobre a organização do trabalho por projetos e SDs - Unidade 06, "Alfabetização em foco: projetos didáticos e sequências didáticas em diálogo com os diferentes componentes curriculares". Bueno e Kleiman (2017), ao analisarem os cadernos, em especial a Unidade 06 , destacam que, ainda que as seções tenham sido elaboradas por autores diferentes, todos justificam como aporte teórico de 
referência os trabalhos de Dolz e Schneuwly (2004). As autoras prestam-se à análise bastante criteriosa das propostas presentes no material do Pacto e, dentre as conclusões, apontam-se algumas: perguntas não pertinentes para a exploração do gênero; SD articulase em torno de tema e pouco aborda o gênero que foi focado; não aparecem atividades de compreensão dos textos concretos do gênero em foco; corresponde ao sentido tradicional de SD (qualquer grupo de atividades) e ao trabalho com um tema ou conteúdo didático específico (hibridização da noção de SD); objetivo instrucional da produção final destoa dos gêneros lidos e trabalhados nas atividades. Sobre o material produzido para o $3^{\circ}$ ano do ensino Fundamental (Ano 3), concluem ser o que apresenta proposta mais próxima do modelo de SD defendido por Dolz e Schneuwly (2004), indicam que há atividades do tipo exploratórias, de sistematização e avaliativas, apontam ênfase nas características do gênero, não em textos concretos representativos, e presença de questões metagenéricas (sistematização de características), mas não de compreensão do texto lido. Bueno e Kleiman (2017) consideram, ainda, que essa ênfase das SDs sobre o tema é possível por se tratar de crianças que estão sendo introduzidas aos diversos discursos, no entanto, destacam que o que é tratado deve ser relevante para elas. No tocante à leitura, apontam que as atividades estão voltadas somente para o letramento escolar, o que merece ser revisto.

O município pesquisado adota plano de ensino comum a toda a rede, determinando a esfera de circulação, o conteúdo de trabalho - os gêneros - e as habilidades pretendidas. Os procedimentos de trabalho e a avaliação são determinados pelas escolas. No $1^{\circ}$ bimestre, a esfera de circulação é literária (verso) e os gêneros de trabalho são: poemas, poema narrativo e cantigas tradicionais. № $2^{\circ}$ bimestre, privilegiase a esfera cotidiana e abordam-se os gêneros regras de jogo, receita, bilhete, carta, convite e propaganda. No $3^{\circ}$, a esfera de circulação é a literária (prosa) e foca-se nos gêneros fábula, lenda, mito, literatura infantil e história em quadrinhos. No $4^{\circ}$ bimestre, há duas esferas de circulação, escolar e jornalística, e os gêneros de trabalho são: verbete de curiosidade e de enciclopédia infantil, artigo de divulgação científica, primeira página do jornal (lide, foto, índice, manchete), notícia e comentário de notícia.

Quanto à organização do trabalho por SDs, Cunha (2014, p. 122) explica que

Do ponto de vista didático, o procedimento envolve objetivos de aprendizagem definidos em termos de desenvolvimento das capacidades de expressão oral e escrita e leva à delimitação de objetos didáticos (objetos de aprendizagem, ensino e avaliação), tomando a língua em uso e os gêneros textuais como eixo central. Do ponto de vista pedagógico, a perspectiva de uso, na qual o dispositivo se estrutura, motiva atividades de produção e reflexão sobre as produções: em uma sequência didática exige-se ampla participação dos aprendentes (que são sujeitos da aprendizagem, mas também sujeitos de linguagem) na construção dos conhecimentos e na regulação de suas produções, com a mediação do professor.

Cagliari (1994, p. 8) considera que "A compreensão da natureza da escrita, de suas funções e usos é indispensável ao processo de alfabetização. Mas o que se vê comumente, nas salas de aula e nos livros didáticos, é um total desconhecimento do assunto". Não se pode ignorar que o livro didático ainda é uma voz que fala alto nas salas de aula e não é essa presença que se critica aqui. O livro didático é um recurso, como tantos outros que estão disponíveis aos professores. O seu uso, no entanto, é objeto de reflexão neste trabalho na análise das práticas planejadas e a cultura de organização de 
trabalho que esse material, tradicionalmente, impôs ainda mostra seus reflexos na forma como os professores pesquisados organizam seus "semanários".

Alves Filho (2011, p. 73) chama a atenção para a necessidade de se ter clareza a respeito do que se constitui um ensino da linguagem com base na noção de gêneros para que não se caia na armadilha de "[...] apenas mudar os nomes e os rótulos, qual seja bradar que 'agora ensinamos e trabalhamos gêneros', mas sem que isso signifique uma mudança substancial (e positiva) nas práticas de ensino-aprendizagem". O autor enfatiza a importância de se pensar e planejar, com fundamentação teórica relevante, as práticas que carecem ser desenvolvidas e integrarem o cotidiano escolar para que se atinja o objetivo da formação do aluno leitor e escritor de textos.

Dolz e Schneuwly (2004) advertem sobre a problemática da transposição didática no que concerne ao ensino de gêneros na escola, já que, vindos de outras esferas que não a escolar, circularão numa esfera que não a sua de origem, havendo o processo de "escolarização" do conhecimento, como já ocorre com outras áreas curriculares. A crítica parte do pressuposto de que essa escolarização acabe por distanciar o objeto de ensino da realidade, quando, na verdade, deveria oportunizar o oposto, ou seja, a sua vivência. Segundo Barbosa e Rovai (2012, p. 29),

Dessa maneira, formam-se "especialistas" em gêneros (ou repetidores de suas características), e não leitores literários, de periódicos, de textos de divulgação científica, tampouco produtores de textos que, efetivamente, tenham o que dizer, que possam contribuir com debates sociais, posicionar-se criticamente em relação aos fatos do mundo e às produções culturais. Alunos submetidos a um trabalho equivocado com gêneros produzirão, no máximo, textos adequados a várias situações sociais hipotéticas e às propriedades do gênero em questão.

Diante do exposto, entende-se que o olhar para o planejamento docente torna-se necessário e configura-se uma rica possibilidade de análises para os encaminhamentos formativos.

\section{Planejamento docente: atividades propostas na escola $\mathrm{A}$}

A análise dos planejamentos da escola $\mathrm{A}$ se deu a partir de quatro semanas analisadas. Não se teve acesso ao planejamento da semana de 22/02 a 26/02/2016 porque a professora não encontrou o material produzido e trabalhado.

$\mathrm{Na}$ semana de 25/04 a 29/04/2016, priorizou-se o trabalho com cantigas populares. Gomes e Moraes (2013, p. 56-57) justificam tal escolha "[...] pelo fato de a convivência com parlendas, as quadrinhas e cantigas remeter a criança a uma relação vivencial com a linguagem lúdica e poética"; além de muito apreciadas pelas crianças, é possível facilmente memorizar pela repetição, dada a sonoridade, a cadência e o ritmo das composições, ocupando "[...] papel importante no processo de alfabetização e nas práticas de letramento, não só pela sua familiaridade com o discurso da criança, mas também por favorecerem, de modo lúdico, a conquista da linguagem”.

Para Teberosky e Colomer (2003), cantando as cantigas, as crianças fazem a distinção de signos orais, aprendem sobre o gênero e estabelecem relações entre o oral e o escrito. No planejamento das professoras, um ponto que pode ser destacado é a proposição de que as crianças cantem as cantigas populares, no entanto, isso não acontece 
no contexto da brincadeira: há atividades escritas que pedem a identificação da função do texto - divertir -, mas não se tem garantido um só momento para que as crianças brinquem, colocando em jogo o conhecimento que têm sobre o gênero. As cantigas aparecem como textos que trazem perguntas a serem respondidas pelos alunos, assim sendo, o aspecto lúdico não se estabelece na proposta. A identificação da "função do texto" é dada como informação ou aparece como pergunta; não se vincula a vivências em que o texto exista e tenha um porquê. Devitt (2009) defende os gêneros como objeto de ensino-aprendizagem desde que com significado social e cultural.

Além das questões de entendimento do conteúdo do texto, aparecem perguntas acerca das rimas, do número de versos e de estrofes. Não se trata de uma SD organizada, há uma justaposição de atividades, que ficam na superficialidade textual, em dias distintos, a partir dos gêneros cantigas e poema. Em uma das cantigas trabalhadas, pedese que sejam circuladas as palavras dissílabas presentes no texto. Sobre esse tipo de atividade, importa trazer as considerações de Travaglia (2013, p. 53, grifo do autor): "[...] a última opção configuradora da metodologia a ser usada é se queremos formar um usuário competente da língua ou um analista da língua”.

Aspecto que pode ser destacado nas propostas da escola A é que os alunos são colocados em situação de leitores para a classe nos momentos de leitura deleite, prática trabalhada no PNAIC e que parece ter sido incluída na rotina da escola pesquisada. A validade da ação também se analisa por se entender que os poemas selecionados, por serem textos curtos, oportunizam às crianças maior segurança nessa atuação.

Na semana de 06/06 a 10/06/2016, o trabalho centra-se em textos instrucionais: receita culinária e passo a passo para montar uma maraca, instrumento musical semelhante a um chocalho. Não há situações de produção textual; os textos e as atividades propostas são retirados do livro didático adotado pela unidade. Novamente não se constata SD organizada, mas uma série de atividades a partir do texto apresentado. Não há situação comunicativa definida que justifique o trabalho com os gêneros abordados. Evidencia-se a ação docente voltada especificamente ao cumprimento do plano de ensino, que estabelece como habilidades a identificação dos elementos constitutivos da organização interna das regras de jogos e receita e o exame do uso das formas verbais no infinitivo ou no imperativo para executar as instruções. As questões abordadas incidem na finalidade do gênero, na estrutura formal do texto e nas características da linguagem. No entanto, é importante destacar que esses encaminhamentos não são construídos com as crianças em situações de leitura e uso do gênero; são dadas como informações organizadas numa espécie de resumo para estudo.

$\mathrm{Na}$ semana subsequente, de 13/06 a 17/06/2016, inicia-se o trabalho com uma produção de texto sobre a festa junina ocorrida na escola. Não há indicação de gênero nem de situação comunicativa a que a produção atenda. Colello $(2012$, p. 73$)$ reflete sobre a escrita na escola, muitas vezes “[...] determinada pelo exercício preparatório, pela elaboração de tarefas específicas, artificiais e descontextualizadas, que inibem a própria interlocução". No caso de escrever sobre a festa junina, pergunta-se: escrever por quê? Para quem? Com que finalidade? Para circular onde? Fica evidente, nesse caso, que é uma escrita para o professor, denotando a questão crucial por que passam os docentes de pensar a produção textual tal qual vivenciaram na escola quando alunos. Sabem que é preciso mudar, mas nem sempre se desprendem das amarras da escrita tão somente como exercício escolar. Novamente, não se tem aqui uma SD, mas um agrupamento de 
atividades. Também não foi pensado sobre o agrupamento de gêneros de uma mesma esfera comunicativa, analisando-se a proposta da semana subsequente.

A segunda proposta da semana retoma os textos instrucionais e evidencia o gênero regra de jogo. A professora faz questionamentos sobre a brincadeira "Batata quente" e pede para que os alunos expliquem verbalmente a regra que conhecem, confronta as versões da brincadeira trazidas por eles e propõe que brinquem no pátio da escola a partir do que as crianças explicaram. Essa dinâmica é muito importante porque coloca em evidência o saber do aluno, destaca a sua participação e o coloca como ator no fazer da aula. Pelo planejamento, entende-se que depois de brincarem com as regras apresentadas pelas crianças é colocada ao grupo a regra trazida pela professora e se propõe a produção coletiva das regras que foram apresentadas oralmente pela turma.

Uma das aulas da semana foca no estudo dos verbos. Há uma informação aos alunos de que os verbos "podem indicar" tempo e pessoa, no entanto, todas as atividades que são apresentadas dizem respeito ao modo, em especial o imperativo.

A produção de texto é solicitada no fechamento das atividades da semana como tarefa: escrever a receita preferida da família. Para a sua elaboração, apresenta-se um "esquema" para a criança organizar sua escrita. Oferecer orientações para estruturar o texto pode ajudar as crianças no atendimento da tarefa, no entanto, atenta-se mais uma vez por não ser percebida a situação comunicativa na qual essa escrita estará envolvida e fará sentido. Não se constata, também, por quais processos de refacção esses textos passarão. Assim, ainda que situações de produção estejam permeando as propostas, é importante pensar momentos de revisão, refacção e reescrita desses textos para atender a uma situação comunicativa definida e com intencionalidade.

A semana de 08 a 12/08/2016 inicia-se com duas propostas de produção: uma individual e uma coletiva. A produção individual trata da elaboração de uma fábula com uma moral já estabelecida e comum a todos. A coletiva diz respeito à compilação dos textos produzidos individualmente em um "livrinho de fábulas produzidas pela classe", havendo a indicação de que será feita a correção coletiva de todos os textos que serão "passados a limpo para a produção do livrinho". Essa etapa do trabalho está prevista para a aula da segunda-feira, o que também destaca a ideia de que o texto deve ser produzido, revisado e concluído em uma aula, no caso uma parte do período, o que significa algo em torno de duas a três horas. Ainda que fosse destinado todo o período da segunda-feira, julga-se o tempo insuficiente. Se a produção textual integra um processo, há de ser considerado o tempo para o seu adequado desenvolvimento, caso contrário, é reforçada a concepção de que o texto é um produto acabado, que o fazem bem e rapidamente quem tem o "dom", a "facilidade de escrever". A escola deve trabalhar para dotar a todos das competências leitora e escritora.

$\mathrm{Na}$ atividade do dia posterior ao da produção, é trabalhada a caracterização dos personagens, o estereótipo que os animais assumem nas fábulas. No entanto, isso é dado inicialmente como informação: raposa/esperta; pavão/vaidoso; cobra/traiçoeira; formiga/trabalhadora. Se a intenção docente é evidenciar a adjetivação comum aos personagens, essas constatações poderiam ser construídas com as crianças a partir da leitura de diversas fábulas em que se confrontassem as características dos animais, observando-se a recorrência dos adjetivos utilizados para cada um deles, o que talvez se configuraria atividade mais rica e significativa. Levar o aluno a entendimentos desse tipo parece ser sempre mais produtivo do que oferecer um conhecimento pronto. 
Há, também, a proposição de uma atividade de trilha, com nomes de animais e adjetivos; é mais um exercício para reconhecimento de classe gramatical do que relacionada ao gênero em estudo. Os adjetivos aparecem todos antepostos aos substantivos a que se referem, o que não é comum na linguagem da criança, tampouco na linguagem popular, que coloca o termo posposto ao substantivo. Não que isso não possa ser apresentado, mas há construções que soam estranhas até a leitores mais experientes, como é o caso de "brincalhão fantasma", "fundo buraco", "movediça areia"; trata-se, somente, de uma atividade de circular adjetivos.

$\mathrm{Na}$ atividade planejada para a quinta-feira da semana em referência, é trabalhada uma fábula, com alguns questionamentos sobre o título e seu entendimento. As questões não fazem refletir sobre o enredo, nem mesmo a moral apresentada, tampouco abordam a imagem que acompanha o texto, toda cheia de significado. Solicita-se, ainda, a definição de uma característica que represente o personagem. No encerramento da semana, indicase a correção coletiva da produção de textos, inferindo-se que seja a mesma da segundafeira, mas isso não fica evidente.

Percebe-se que o planejamento da escola $\mathrm{A}$ está bem vinculado às atividades apresentadas pelo livro didático adotado, o que foi incentivado nos encontros do Pacto no município. Souza $(1999$, p. 27) reflete sobre o livro didático:

O caráter de autoridade do livro didático encontra sua legitimidade na crença de que ele é depositário de um saber a ser decifrado, pois supõe-se que o livro didático contenha uma verdade sacramentada a ser transmitida e compartilhada. Verdade já dada que o professor (legitimado e institucionalmente autorizado a manejar o livro didático) deve apenas reproduzir, cabendo ao aluno assimilá-la.

Ainda sobre essa influência no planejamento docente, Rojo (2003, p. 98-99) destaca que é importante considerar que há uma série de exigências para o trabalho com a linguagem oral e escrita "[...] - centrais, no processo de letramentos - que ainda estão longe da realidade dos LDs que circulam em nossa rede pública hoje”.

\section{Planejamento docente: atividades propostas na escola B}

Em relação aos gêneros do primeiro bimestre, cabe ressaltar a importância que se atribui ao texto poético. Muitas vezes, diante do recorrente discurso da funcionalidade dos textos e de um recorte que responde a objetivos um tanto quanto reducionistas sobre o que é ensinar Língua Portuguesa, os professores tendem a questionar a presença de textos literários em programas oficiais. Não raro indaga-se acerca do que ensinar sobre poema, como trabalhar sua função na sociedade, entre outros questionamentos que indicam um entendimento de que o ensino da língua deva acontecer separado do ensino da literatura. Essa insistência por ensinar a "função social" do gênero faz com que se percam aspectos importantes a que o gênero se presta. Humanizar, pois, seria uma das funções do texto literário, permitir a fruição, o encantamento, tomar para si a palavra do outro para o próprio gozo. Leite (2011) afirma que a escola tem uma visão reduzida de literatura e reforça ser necessária a superação da concepção tradicional que orienta as abordagens e que reduz as possibilidades de trabalho, devendo o ensino de língua e literatura acontecer de forma integrada numa mesma prática, desde a alfabetização. 
No caso da primeira semana analisada, de 22/02 a 26/02/2016, percebe-se o uso do poema voltado à discussão dos temas abordados: o nome e o sobrenome a partir da música "Gente tem sobrenome", de Toquinho, e do poema "Nome da gente", de Pedro Bandeira; a identificação de informações explícitas de "As meninas", de Cecília Meireles, também utilizado para o preenchimento de palavras (texto lacunado) e da identificação de versos, estrofes e rimas. Há uma proposta de "brincar com rima", que apresenta um poema construído com substantivos próprios que pedem a definição de adjetivo para estabelecimento de rima, mas as frases revelam certa incoerência por não haver um predicado evidente.

A atividade de produção, a reescrita do poema trabalhado, aparece, tal qual nos livros didáticos, como finalização da semana, não havendo apontamentos de quais estratégias seriam utilizadas pelas docentes para fazer a "correção coletiva" do poema.

$\mathrm{Na}$ segunda semana selecionada para análise, percebe-se uma organização do trabalho em "momentos", o que, nos estudos de Dolz e Schneuwly (2004), foram denominados "módulos". Merece destaque o entendimento que os docentes possuem acerca de "análise linguística" na SD. Nesse sentido, destacam-se propostas de atividades como: "pinte de vermelho o título do poema"; "enumere os versos"; "circule de amarelo as estrofes"; "grife as rimas de azul". Verifica-se que, para os professores pesquisados na escola B, o conceito de "análise linguística" recai sobre o reconhecimento da estrutura composicional do gênero poema. Sobre esse aspecto, é válido considerar o que Wachowicz (2010, p. 14) esclarece:

[...] na régua baixa, análise linguística não é levantamento de fatores contextuais que condicionam um texto a ser o que é. Análise linguística não é - no seco - tratamento sociopragmático do texto; não é puramente a análise das vozes ideológicas do fio discursivo; e também não é simplesmente conteúdo temático que provoca sua construção argumentativa. É tudo isso voltado à língua.

A produção textual aparece no $6^{\circ}$ momento, solicitando que as crianças escrevam um poema de duas estrofes sobre o sonho que possuem. Não há indicação do que será feito com o texto dos alunos nem momento posterior que sinalize a questão da intervenção docente, tampouco propostas de reescrita. A proposição de escrever um poema aparece, assim, para o cumprimento de "[...] fins tipicamente escolares, mascaram o alcance da conquista da escrita, tornando-a artificial e, muitas vezes, desprovida de significado ou motivação" (COLELLO, 2012, p. 26).

Gonçalves (2010, p. 122-123), ao defender que o processo de reescrita integra o processo de escrita, principalmente por meio de SDs e de gêneros textuais, explana que

A revisão/reescrita é parte integrante da atividade escrita. Assim como o grupo de Genebra, entendemos a atividade de reescrita como passível de ser aprendida. Pasquier e Dolz (1996) propõem que, na fase de aprendizagem de um gênero textual qualquer, haja uma distância temporal entre a primeira versão e a versão final. Os autores já observaram, em produções de textos francófonos, que deve haver tal distanciamento a fim de que o estudante reflita sobre a própria produção.

No $9^{\circ}$ momento, é proposta uma atividade relacionada aos tempos verbais, solicitando que os alunos atentem para o uso dos verbos nos poemas de Cecília Meireles "A Bailarina", com indicação de futuro a longo prazo, e "O Menino Azul”, com indicação 
de um desejo atual. Determina-se que os alunos passem sentenças que são apresentadas no futuro para o presente. As frases não estão relacionadas entre si, são desvinculadas de um contexto, configurando-se um exercício semelhante aos apresentados em gramáticas normativas, numa perspectiva bastante tradicional de abordagem da língua. No $10^{\circ}$ Momento, apresenta-se um poema e solicita-se que as crianças grifem as palavras femininas e passem-nas para o masculino. Sobre proposições desse tipo, vale considerar Antunes (2014, p. 17, grifo da autora), para quem não se pode

[...] abrir mão do princípio de que nossas concepções acerca da linguagem e de seus componentes são o fundamento de tudo o que rege o trabalho pedagógico, pois, para perceber fatos, precisamos da teoria. Noutras palavras: as pessoas podem ser tão inteligentes quanto possível, mas só conseguem ver o que a teoria que adotam lhes permite ver", como afirma Possenti em Língua na mídia (2009, p. 31).

Não há, em nenhuma das duas sequências que integram o primeiro bimestre, situações de leituras de livros de poemas, de descoberta dos sentidos das palavras no texto, de estímulo à recitação ou à escuta e à apreciação, como apresentado nas habilidades a serem desenvolvidas no bimestre. As leituras propostas são todas voltadas para responder a questões sobre o conteúdo dos poemas.

A quinzena do segundo bimestre analisada, de 06/06 a 17/06/2016, apresentou duas SDs envolvendo gêneros da esfera cotidiana: bilhete e carta. A única habilidade descrita no plano de ensino relacionada a tais gêneros é "dar recados e esclarecer eventuais dúvidas do interlocutor". Percebe-se, por habilidades descritas no plano, que a ênfase é dada aos textos injuntivos, especificamente à receita e à regra de jogo.

É possível notar, na semana de 06/06 a 10/06/2016, aproximação ao modelo de SD sugerido por Dolz e Schneuwly (2004). O planejamento se inicia com uma produção inicial, no entanto, a situação comunicativa apresentada se mostra um arranjo entre professoras de períodos diferentes e não se percebe real necessidade de interação verbal de forma a exigir a participação efetiva dos educandos (COSTA-HÜBES; SIMIONI, 2014). Há a leitura de um livro, cuja preocupação parece recair sobre a identificação do gênero textual bilhete, utilizado por um dos personagens, como se verifica no questionamento "Qual gênero textual aparece no decorrer da história?".

A segunda etapa tem como proposta a comparação de linguagem formal e informal em bilhetes, o que pode ter sido uma atividade bem interessante para alunos de $3^{\circ}$ ano, dependendo da mediação feita pelo docente. Porém, o bilhete considerado "informal" não corresponde ao que na vida cotidiana utilizamos com esse caráter, uma vez que, para exemplificar a informalidade, foi tomado como exemplo o bilhete enviado pela professora do período inverso. As perguntas que aparecem, também, não exploram os traços da linguagem que um ou outro possa apresentar: "Eles são iguais? Qual é a diferença entre os dois bilhetes?". A estrutura do gênero é trabalhada como informação dada e somente depois solicita-se, por um exercício de pintar partes do texto, que as crianças identifiquem os elementos estruturais. Esse tipo de atividade é recorrente na prática de professores, como constata Albuquerque (2006, p. 74):

Mais do que possibilitar aos alunos leituras/escritas diversas, de diversos gêneros, escritos em contextos diferenciados e para diferentes fins, a ênfase no trabalho com textos tem recaído no ensino de suas características, na necessidade dos alunos de identificá-los e classificá-los. Não se nega, aqui, a importância desse conhecimento, mas o que se observa 
é uma escolarização desses textos como conteúdos, distanciada de seus contextos sociais de produção.

Não se trata de acusar o professor nessa tentativa de ensinar aos alunos o que dominam e creem que as crianças precisam saber, mas é reconhecida uma falha no plano de ensino, que deixa o trabalho com o gênero num campo muito amplo e dá margem para que os professores busquem o foco no que têm segurança, nesse caso, na identificação dos elementos estruturais. Isso também não é uma postura específica do grupo pesquisado. A esse respeito, Marcuschi (2010, p. 75-76) discorre que

Nos últimos quinze anos, mudanças significativas ocorreram no tratamento dispensado ao ensino da elaboração de texto no âmbito escolar. Na segunda metade dos anos 1990, o estudo dos gêneros textuais assumiu espaço expressivo no contexto da sala de aula. De início, predominou o interesse pela nomeação e classificação dos gêneros textuais e, em decorrência, pela caracterização de seus aspectos formais, tratados como fixos. Nesse sentido, a abordagem com base nos gêneros textuais não se diferenciava muito dos estudos estruturais pleiteados pela gramática e a preocupação maior da escola e dos livros didáticos centrava-se no "ensino dos gêneros textuais" em si e por si mesmos, à revelia do processo sociointeracional.

Reflete, ainda, que

O professor também precisa ter clareza de que, tomar um conto, um bilhete, uma notícia, dentre outros gêneros possíveis, como objeto de ensino, requer um percurso pedagógico distinto, pois, mais do que levar o aluno a compreender os aspectos formais que organizam os diferentes gêneros textuais, é fundamental levá-lo a refletir sobre as práticas sociais em que os gêneros se inserem e os discursos e temas que neles circulam (MARCUSCHI, 2010, p. 79).

Essa preocupação com os elementos formais do gênero tomados como fixos é recorrente na proposta analisada, repetindo-se na $3^{\mathrm{a}}$ e na $4^{\mathrm{a}}$ etapas. A $5^{\mathrm{a}}$ etapa retoma a produção inicial e é oferecido aos alunos um quadro para que analisem a produção inicial e final, com perguntas sobre data, cumprimento, destinatário, extensão do texto, facilidade de entendimento do assunto, despedida e assinatura.

De todas as semanas analisadas, o planejamento de 06/06 a 10/06/2016 é o que mais se aproxima dos estudos sobre SD, ainda que as propostas pudessem ser melhoradas para uma exploração que colocasse o aluno mais no centro do processo.

A semana de 13/06 a 17/06/2016 é continuidade da anterior; há, novamente, no $3^{\circ}$ momento, a retomada da estrutura do gênero. No entanto, no $4^{\circ}$ momento insere-se o gênero carta pessoal, que aparece descontextualizado do que se vinha trabalhando. Fica nítida a intenção, no $6^{\circ}$ Momento, de comparar a estrutura da carta com a do bilhete, mas o que se evidencia é, de novo, a "nomenclatura estrutural" antes mesmo da vivência de uma situação comunicativa em que o gênero se mostrasse necessário.

As propostas de produção aparecem no $9^{\circ}$ e no $11^{\circ}$ momentos e se configuram simulacros de escrita: na primeira, ajudar o Charlie Brown, personagem dos quadrinhos do Snoop, a escrever bilhete para a menininha ruiva; na segunda, colocar-se no lugar do Edu, personagem fictício, e responder a um bilhete recebido sobre jogo de futebol. 
A quinta e última semana analisada, de 08/08 a 12/08/2016, adentra o terceiro bimestre e apresentou uma sequência de atividades envolvendo o que, no plano de ensino, é apontado como gênero da esfera literária (prosa): história em quadrinhos (HQ).

Comparando-se a sequência de atividades planejada pela escola B nessa semana e a analisada na Unidade 06, Ano 03, do PNAIC/2013, percebem-se algumas estratégias que se aproximam, como apresentar uma breve biografia de cartunistas conhecidos. A proposta do PNAIC, no entanto, coloca o aluno em contato com gênero desde o Módulo 1 , momento em que as crianças farão a leitura de textos do gênero HQ, com o objetivo de que sejam familiarizadas com o gênero em estudo, o que não acontece na sequência planejada pelas professoras. Essa ideia de colocar o aluno em contato com o gênero para leitura e reconhecimento também é defendida por Costa-Hübes e Simioni (2014), que destacam, ainda, que a forma como a leitura é abordada na sala de aula é reveladora da concepção que se tem de linguagem, e Barros (2014), para quem essa etapa é importante por permitir o reconhecimento do gênero na forma que circula na sociedade.

A produção inicial não aparece na proposta da escola, que já parte para a apresentação dos modelos de balões e para uma conceituação de onomatopeias. Somente depois da apresentação de conceitos é possibilitado o contato com textos do gênero em estudo, com a intenção de responder perguntas e focando no entendimento da história. Não há, nessa situação, exploração dos recursos e da linguagem própria da HQ.

No que pode ser entendido como os dois últimos momentos da sequência (na quinta e sexta-feira da semana de trabalho), já que não apresenta tal divisão, há propostas de produção: a de uma $\mathrm{HQ}$ de seis quadrinhos, em duplas, que, depois, deverá ser transformada em texto narrativo em prosa. Embora a proposta do PNAIC sugira o oposto - transformar fábula ou conto em HQ -, a atividade apresentada pelas professoras atende à habilidade delineada no plano de ensino: transformar HQ em texto narrativo direto e indireto. Revela-se, dessa forma, uma necessidade de repensar e adequar o próprio plano, que leva a um planejamento que considera mais a estrutura formal do texto do que a situação comunicativa em que ele se faz necessário, e apresenta confusões ao solicitar a tipologia, e não um gênero específico, e nomeá-la como direta e indireta, numa referência ao tipo de discurso que se percebe no texto.

Não se pode dizer que há imobilidade docente diante do novo, o que acarretaria a permanência de práticas tradicionais (ALBUQUERQUE, 2006). Ainda que mínimos, percebem-se elementos de apropriação das orientações dos documentos oficiais, no caso do plano de ensino, e das reflexões promovidas nos processos formativos, a exemplo do PNAIC. Mais, percebe-se a tentativa das professoras de mudar o seu fazer pedagógico, embora isso nem sempre se concretize em propostas adequadas ao gênero de trabalho. É o que as professoras sabem e conseguem fazer no momento. Por isso, é importante retomar as palavras de Meirieu (2005, p. 90):

[...] a aprendizagem requer uma disjunção com as aquisições anteriores, ela só pode realizar-se em articulação com "uma base de apoio" que assegure ao sujeito um mínimo de continuidade e de segurança: "só se pode fazer com". Com aquilo que é, a partir daquilo a que se aspira, agarrando-se a fragmentos de habilidades existentes, partindo de algo que se reconhece, de um elemento um pouco mais familiar, dentro daquilo que, para nós, é, de início, um objeto opaco, sempre um pouco misterioso e inquietante. É assim que se aprende o que se ignora..., mas sempre a partir do que já se sabe. 
E os professores estão aprendendo. Não na velocidade que a realidade que se tem exige, mas certamente a partir do que já sabem, num processo de desconstrução do que há arraigado, de desprendimento das verdades prontas dos livros didáticos, de descoberta da marca que cada professor pode deixar.

\section{À guisa de conclusão: os diálogos percebidos entre a escola $\mathrm{A}$, a escola $\mathrm{B}$ e o PNAIC}

O PNAIC colocou em cena importantes questões que devem integrar o trabalho docente, no seu fazer cotidiano, e o processo formativo, pensado coletivamente pelas equipes escolares. Versou sobre o planejamento e a organização do trabalho dos professores, evidenciou e se propôs a analisar SDs, elucidou a necessidade do trabalho com gêneros textuais. A parte teórica do programa no tocante a esses temas merece ser revisitada de forma crítica sempre pelos docentes e pelos gestores. No entanto, sabe-se que a teoria não sustenta uma prática inovadora se não houver mudanças de concepções de ensino. Sobre a mudança de concepção docente, Ferreira (2013, p. 64) esclarece que "Vários autores (HEWSON, 1992; HOY; DAVIS; PAPE, 2006) argumentam que os professores só mudam as suas concepções quando as colocam em questão ou são confrontados com outras mais significativas".

A escola A e a escola B buscam cumprir o plano de ensino. Em dadas situações, percebe-se maior autoria ${ }^{2}$ docente no planejamento da escola $\mathrm{B}$, enquanto a escola $\mathrm{A}$ se mostra mais presa ao livro didático. No entanto, não se pode desconsiderar que a escola A coloca o aluno em alguns momentos como partícipe mais ativo - na leitura deleite e na brincadeira -, o que não se percebe com clareza na proposta da escola B. Em ambas, há, nos Planos de aula, resquícios do trabalho desenvolvido pelo PNAIC, bem como de formações desenvolvidas pela própria Secretaria Municipal de Educação, mas não se pode dizer que houve apropriação plena de conceitos e de concepções de ensino trabalhadas na formação continuada oferecida aos professores alfabetizadores. No entanto, todo passo tem valor e não pode ser desprezado como avanço.

Há, nas duas escolas, uma lacuna no trabalho de análise linguística, de produção textual e de intervenção docente sobre a escrita do aluno. A abordagem está centrada na "forma" dos gêneros, numa estrutura entendida como fixa, e menos ao seu conteúdo e à função que possuem no contexto comunicativo. Não se refere aqui, também, ao entendimento prático que se tem dessa função: instruir, divertir, informar, por exemplo. Não raro, percebe-se essa identificação dada como informação pronta, não como fruto de construção e de exploração do gênero num contexto significativo. A identificação dessas dificuldades docentes na organização do trabalho pedagógico poderia servir à elaboração de planos de formação por parte dos gestores de cada unidade.

Assumir uma perspectiva de trabalho que vise à formação de leitores e escritores competentes exige que o texto esteja presente na sala de aula diferentemente do que tem se verificado. Deve-se refletir sobre os encaminhamentos propostos para que se constate

\footnotetext{
${ }^{2} \mathrm{O}$ termo autoria no texto foi utilizado para fazer referência a um planejamento elaborado pelo professor, que reflita também suas escolhas sobre os materiais de trabalho. No entanto, reconhece-se que a questão da autoria docente vai além da atitude de "criação/elaboração" de planejamentos e materiais próprios. Para Cardoso (2016, p. 9), "No contexto da sala de aula, o professor vivencia a dinâmica da autoria, na medida em que dá sentido às suas práticas, tentando solucionar problemas, potencializar o aprendizado dos estudantes. A criação de soluções para atuar pelo professor constitui-se num ato autoral".
} 
que o trabalho desenvolvido seja, de fato, caminho para a aprendizagem da criança. A escola, na designação mais ampla, e os professores assumem o discurso do caráter dialógico da produção escrita, mas ainda se mostram presos à escrita como exercício escolar. Perpetuam, assim, práticas que vivenciaram e que ainda são uma "verdade" forte dentro de cada um.

Muitas vezes, espera-se que a mudança venha mesmo "embalada", de fora para dentro, fica-se à espera de determinações de instâncias superiores, entretanto, à medida que se percebem resultados, a adesão a novas ideias e a experimentação de práticas diferentes são mais facilmente trabalhadas porque as inovações são aceitas e compreendidas como necessárias. O PNAIC pode ter sido entendido assim, como a solução que vem de fora, contudo não basta que um programa de formação oriente para determinadas práticas, ajude a pensar em ações que acontecem para fins de devolutivas aos formadores no período de sua duração. É necessário que o fazer do professor seja melhor pensado, por ele, por seus pares e por seus formadores.

Sintetizando os apontamentos sobre o planejamento das escolas A e B, podem ser constatados alguns equívocos apontados por Alves Filho (2011) e analisados por Bueno e Kleiman (2017) no material do PNAIC, mas também se percebem os encaminhamentos adequados que as professoras propuseram, mesmo com as lacunas que o processo formativo tenha revelado.

\section{REFERÊNCIAS}

ALBUQUERQUE, E. B. C. de. Mudanças didáticas e pedagógicas no ensino da língua portuguesa: apropriações de professores. Belo Horizonte: Autêntica, 2006.

ALVES FILHO, F. Gêneros jornalísticos: notícias e cartas de leitor no ensino fundamental. São Paulo: Cortez, 2011.

ANTUNES, I. Gramática contextualizada: limpando o "pó das ideias simples". São Paulo: Parábola Editorial, 2014.

BARBOSA, J. P.; ROVAI, C. F. Gêneros do discurso na escola: rediscutindo princípios e práticas. São Paulo: FTD, 2012.

BARDIN, L. Análise de conteúdo. São Paulo: Edições 70, 2011.

BARROS, E. M. D. de. As reconcepções do trabalho docente no processo da transposição didática de gêneros. In: BARROS, E. M. D. de; RIOS-REGISTRO, E. S. (Org.). Experiências com sequências didáticas de gêneros textuais. Campinas: Pontes Editores, 2014. p. 41-68.

BRASIL. Secretaria de Educação Básica. Diretoria de Apoio à Gestão Educacional. Pacto nacional pela alfabetização na idade certa: planejamento e organização da rotina na alfabetização: ano 3: unidade 2. Ministério da Educação, Secretaria de Educação Básica, Diretoria de Apoio à Gestão Educacional. Brasília: MEC, SEB, 2012.

BRASIL. Secretaria de Educação Básica. Diretoria de Apoio à Gestão Educacional. Pacto Nacional pela Alfabetização na Idade Certa. Interdisciplinaridade no ciclo de alfabetização. Caderno de Apresentação. Ministério da Educação, Secretaria de Educação Básica, Diretoria de Apoio à Gestão Educacional. Brasília: MEC, SEB, 2015. 
BUENO, L.; KLEIMAN, A. Avaliação de leitura, sequências didáticas e letramento no PNAIC: (im)possíveis articulações? In: CORDEIRO, G. S.; BARROS, E. M. D.; GONÇALVES, A. V. Letramentos, objetos e instrumentos de ensino: gêneros textuais, sequências e gestos didáticos. Campinas: Pontes Editores, 2017.

CAGLIARI, L. C. Alfabetização \& Linguística. 7. ed. São Paulo: Scipione, 1994.

CARDOSO, G. M. M. As possibilidades de construção da autoria na formação do professor-discente do PARFOR. In: ENCONTRO INTERNACIONAL DE FORMAÇÃO DE PROFESSORES (ENFOPE), 9., 2016. Sergipe. Anais eletrônicos do $9^{\circ}$ ENCONTRO INTERNACIONAL DE FORMAÇÃO DE PROFESSORES (ENFOPE), Sergipe: Universidade Tiradentes, v. 9, n. 1. Disponível em $<$ https://eventos.set.edu.br/index.php/enfope/article/viewFile/2459/500>. Acesso em: 13 ago. 2018.

COLELlO, S. M. G. A escola que (não) ensina a escrever. 2. ed. revisada. São Paulo: Summus, 2012.

COSTA-HÜBES, T. da C.; SIMIONI, C. A. Sequência didática: uma proposta metodológica curricular de trabalho com os gêneros discursivos/textuais. In: BARROS, E. M. D. de; RIOS-REGISTRO, E. S. (Org.). Experiências com sequências didáticas de gêneros textuais. Campinas: Pontes Editores, 2014. p. 15-40.

CUNHA, M. C. A sequência didática na perspectiva da avaliação formativa: uma proposta para a produção/avaliação de textos nos nove anos do ensino fundamental. In: LEAL, T. F.; SUASSUNA, L. (Orgs.). Ensino de Língua Portuguesa na Educação Básica: reflexões sobre o currículo. Belo Horizonte: Autêntica Editora, 2014. p. 117-143.

DEVITT, A. Teaching critical genre awareness. In: BAZERMAN, C.; BONINI, A.; FIGUEIREDO, D. Genre in a changing world. Fort Collins, Colorado: The WAC Clearinghouse, 2009, p. 337-351.

DOLZ, J.; SCHNEUWLY, B. Gêneros orais e escritos na escola. Campinas: Mercado de Letras, 2004.

FERREIRA, C. R. O uso de visualizações no ensino de química e de física: a formação pedagógica dos professores. 2013. 733 f. Tese (Doutorado) - Faculdade de Educação, Instituto de Física, Instituto de Química e Instituto de Biociências. Universidade de São Paulo, São Paulo. Disponível em: $<$ www.teses.usp.br/teses/disponiveis/81/81132/tde.../Celeste_Rodrigues_Ferreira.pdf $>$. Acesso em: 30 abr. 2017.

FREIRE, P. Pedagogia da autonomia: saberes necessários à prática educativa. São Paulo: Paz e Terra, 2011.

GOMES, L.; MORAES, F. Alfabetizar letrando com a tradição oral. São Paulo: Cortez, 2013.

GONÇALVES, A. V. Gêneros textuais na escola: da compreensão à produção. Dourados: Editora da UFGD, 2010.

LEITE, L. C. de M. Gramática e Literatura: desencontros e esperanças. In: GERALDI, J. W. (Org.). O texto na sala de aula. 5. ed. São Paulo: Ática, 2011. p. 17-25. 
MARCUSCHI, B. Escrevendo na escola para a vida. In: BRASIL. Lingua Portuguesa: ensino fundamental. Coleção Explorando o Ensino, v. 19. Coordenação: RANGEL, E. de O.; ROJO, R. H. R. Brasília: Ministério da Educação, Secretaria de Educação Básica, 2010. p. 65-84.

MEIRIEU, P. O cotidiano da escola e da sala de aula: o fazer e o compreender. Porto Alegre: Artmed, 2005.

NEDER, M. L. C. Concepções de linguagem e o ensino de língua portuguesa. Polifonia, v. $0, \quad$ n. $00, \quad 1993 . \quad$ p. 71-89. Disponível em: $<$ http://periodicoscientificos.ufmt.br/ojs/index.php/polifonia/issue/view/134>. Acesso em: 02 ago. 2017.

ROJO, R. O perfil do livro didático de língua portuguesa para o ensino fundamental $\left(5^{\mathrm{a}} \mathrm{a}\right.$ $8^{\mathrm{a}}$ séries). In: ROJO, R.; BATISTA, A. A. G. (Org.). Livro didático de língua portuguesa, letramento e cultura da escrita. Campinas: Mercado de Letras, 2003. p. 69-99.

SOUZA, D. M. de. Autoridade, autoria e livro didático. In: CORACINI, M. J. F. (Org.). Interpretação, autoria e legitimação do livro didático. Campinas: Pontes, 1999. p. 27-31.

TEBEROSKY, A.; COLOMER, T. Aprender a ler $e$ a escrever: uma proposta construtivista. Porto Alegre: Artmed, 2003.

TRAVAGLIA, L. C. Na trilha da gramática: conhecimento linguístico na alfabetização e letramento. São Paulo: Cortez, 2013.

WACHOWICZ, T. C. Análise Linguística nos Gêneros Textuais. Curitiba: Ibpex, 2010.

Recebido em: 26/08/2017

Aprovado em: 21/08/2018 